\title{
Easy, but not that much: how easy ontology can get complicated
}

\author{
César Frederico dos Santos ${ }^{1}$
}

1 E-mail: cesar.frederico@ufma.br Orcid: http://orcid.org/0000-0003-4458-5250

\begin{abstract}
In Thomasson's "easy" approach to ontology, recalcitrant ontological problems are purportedly solved through trivial and straightforward inferences from putatively uncontroversial premises. Easy ontology aims at putting aside the metaphysical quarrels that, according to Thomasson, have led philosophers to think that existence questions were hard to answer. In this paper, I argue that, even if we refrain from engaging in metaphysics and limit our investigations to conceptual and empirical matters, as the "easy" approach recommends, we cannot expect to answer disputed existence questions by trivial and straightforward inferences. The problem is that putative easy-arguments leave room for many contentious issues for which there is no trivial and straightforward answer. To illustrate this point, I discuss some aspects of the debates on the existence of human races and numbers.
\end{abstract}

Keywords: Thomasson's easy ontology; metaphysics; ontology of races; ontology of numbers.

\section{Introduction}

What there is? Philosophers have debated this question for centuries, and apparently will continue doing so in the future. However, from time to time, someone comes up with a methodological proposal that promises to dissolve ontological problems, or to make them easier, almost trivial. This is what Amie Thomasson has recently done in Ontology Made Easy (Thomasson, 2015). She claims that the easy ontology approach "enables existence questions to be easily_often trivially and always straightforwardly_answerable" (Thomasson, 2015, p. 23). Mostly inspired in Carnap, her easy approach is aimed at rendering apparently difficult debates in ontology pointless, "because the question is so easy and obvious to answer (with a 'yes') that serious debates about [it] are out of place” (Thomasson, 2017a, p. 7).

In this paper, I will show that Thomasson's easy ontology framework cannot deliver the easy answers it promises to do. As we will see, this does not mean that easy ontology is an erroneous approach to ontology - in fact, I believe it isn't. The problem is that easy ontology is not actually easy. Even if we refrain from engaging in metaphysics and limit our investigations to conceptual and empirical matters, as the "easy" approach recommends, there is still plenty of room for the emergence of legitimate controversies.

Others have already pointed out difficulties around Thomasson's easy ontology. Tim Button (2016, p. 9), for example, suggests that easy ontology "is something of a misnomer". One problem, according to Button, is that the trivial inferences that should play a central role in easy ontology — the "easy-arguments" rely on ordinary language, and "[o]rdinary language is a wildly complicated phenomenon" (Button, 2016, p. 9).

Here, I will second Button's contention that easy ontology is is a misnomer. However, I will show this through a different argument, from within easy ontology itself. As we will see, the kinds of controversies Thomasson admits within easy ontology, which cannot themselves be settled by easy-arguments, are sufficient to make it a difficult and contentious enterprise. Easy-arguments can be straightforward answers for existence questions only when everything else — the side issues that may legitimately arise from them-has already been settled. In fact, these "side" issues are the most relevant questions when it comes to ontological 
debates, as we will see. Easy-arguments provide no more than initial working hypotheses.

In the next section, I briefly recall the basics of easy ontology, following Thomasson (2015), and discuss ways in which controversies can admittedly arise within the framework. In section 3, I illustrate how some of these legitimate controversies can arise in a real ontological dispute, namely in debates on the existence of human races. In section 4, I show that even when ordinary language usage is more stable and regular - in the domain of numerical expressions_- legitimate controversies can arise as well. To conclude, in section $5 \mathrm{I}$ summarize the main points of this essay.

\section{Easy ontology}

Easy ontology offers a deflationist interpretation of existence-formulated in Schema (E) —, analogous to deflationist treatments of truth and reference. Deflationism, in the sense Thomasson uses it, is the denial "that the relevant concept (of truth, reference, or existence) is even attempting to refer to a substantive property the nature of which we can investigate and hope to discover" (Thomasson, 2015, p. 87). Applied to ontology, deflationism "involves the idea that there is no call for a theory aiming to uncover a deep and substantial nature of existence" (Thomasson, 2015, p. 116). Easy ontology rejects the idea that there is an across-the-board substantive criterion of existence, such as causal relevance, mind-independence, and so on. Thomasson treats 'exists' as a formal term, devoid of substantial content, whose rule of use is given by Schema (E):

E: Ks exist iff the application conditions actually associated with ' $K$ ' are fulfilled,

where ' $\mathrm{K}$ ' is a general noun—such as 'properties', 'tables' or 'numbers' — and 'actually' means in this world (Thomasson, 2015, p. 86). The application conditions of ' $K$ ' are the linguistic rules that govern its use and allow a competent speaker to decide, given an object or concept, if the term ' $K$ ' applies to it or not. Schema (E) plays a central role in easy-arguments. To illustrate this, let us consider an easy-argument Thomasson's gives for the existence of properties:

[A] competent speaker ... is in a position to start from the undisputed observation that Beyoncé's dress is red and move to the conclusion that the dress has the property of redness, and so that there are properties, without reviewing metaphysical debates about properties (Thomasson, 2015, p. 130).

Easy-arguments always start with an uncontroversial truth-in this example, 'Beyoncé's dress is red', assuming we are in Beyoncé's presence and she is actually wearing a red dress. The next step is meant to introduce the term whose referent's existence is in question, and to show that there is something that fulfills its application conditions. In this case, the term is 'property', and what fulfills its application conditions is redness. The inference from the premise to this sentence- 'the dress has the property of redness' - is supposed to be trivial in the context of ordinary language usage. Finally, once it has been shown that the application conditions of the term 'property' are fulfilled, the conclusion follows by Schema (E): “there are properties".

Easy-arguments try to capture our everyday method for solving simple existence questions. The conclusion that there are properties was obtained in the same way we could ordinarily conclude that there are tables from the observation that there is a piece of furniture in this room that is a table. Thomasson claims 
that this intuitive, common way of solving everyday simple existence questions is the proper method for answering the ontological questions that occupy philosophers. The only difference is that in our everyday life, as well as in science, we are mostly concerned with empirical questions, whereas in philosophy we are mostly concerned with conceptual ones. In both cases, however, the solution of existence questions is easy, in the sense that these questions are "easily resolved by simple observations made utilizing conceptual and linguistic competence or by trivial inferences from uncontested truths” (Thomasson, 2015, p. 14).

Empirical investigation and conceptual analysis; this is all we need to settle ontological debates in easy ontology. There is no need for mysterious metaphysical methods.

Mysterious deep metaphysics is the kind of work demanded by hard ontology. The hard ontologist sees herself as "discovering fundamental features of reality-and distinguishing what does and does not really exist" (Thomasson, 2015, p. 13). Against the easy-argument presented above, the hard ontologist would argue that it should have been first shown that redness really exists. For Thomasson, though, when the hard ontologist asks whether redness really exists, she is uttering an ill-formed pseudo-question.

Thomasson's easy ontology is an heir of Carnap (1983). She endorses the Carnapian distinction between internal and external existence questions, relative to a linguistic framework. A linguistic framework consists of terms and rules that govern the use of terms. Internal questions are those pertaining to the existence of an entity within the framework, and external questions are those pertaining to the existence of the system of entities as a whole. The easy ontologist preferably addresses internal questions. The questions of the hard ontologist are seen as external and, following Carnap, as either meaningless or, on a charitable interpretation, pragmatic questions about the adoption of the linguistic framework.

Thomasson explains why internal questions are meaningful and easy, whereas external questions are meaningless, in terms of the use-mention distinction. The meaning of a term in a linguistic framework is given by its rules of use. When a term is used in accordance with them, this is an internal and meaningful use. Internal questions have easy answers because establishing whether the application conditions of the term in question are fulfilled or not is just a matter of following its rules of use and conducting the empirical or conceptual work required by them. When hard ontologists reject an easy answer and ask whether the thing in question really exists, this shows that they are no longer using the term in accordance with its rules of use; otherwise they would have accepted the easy answer. The questions of the hard ontologist are thus external, posed outside the proper linguistic framework. "But if they attempt to use the terms while severing them from [their] rules of use, they make the terms meaningless, and the questions pseudo-questions" (Thomasson, 2015, p. 39-40). External questions interpreted in this way are illegitimate.

Nevertheless, Thomasson can offer the hard ontologist a charitable interpretation of her questions. External questions may be seen as mentioning, rather than using, the terms of the linguistic framework, and raising the pragmatic question of whether we should adopt it or not. Interpreted in this way, the external question 'Do properties exist?' is no longer a question about properties, but a question about the term 'property': should we adopt property-language or not? If the hard ontologist accepts this interpretation, she is no longer engaged in hard ontology, but is taking part in what Thomasson (2017a) calls "metalinguistic negotiation". In metalinguistic negotiation, the disputants are advocating for alternative uses of a term, or for not using a term at all. They have "disagreements about how our terms should be used in a given context" (Thomasson, 2017a, p. 11) and are "involved in advocating for different conceptual schemes with different impact on our way of life" (Thomasson, 2017a, p. 20). Metaphysical debates reframed in these terms become a legitimate enterprise from the perspective of easy ontology. To the extent that metalinguistic negotiations 
can be settled by pragmatic, empirical or conceptual considerations, no epistemically metaphysical method ${ }^{1}$ is required.

External questions interpreted pragmatically differ from internal questions only in the fact that, for the former, easy-arguments are not available. More complex argumentative methods must be recruited, such as considerations about theoretical virtues or impact on our daily life. Since these considerations may be not trivial, this is, therefore, one way in which controversies may legitimately arise in easy ontology. And there are more.

Easy-arguments are not exempt from difficulties of their own. Schema (E) makes room for at least three sources of difficulty. First: sometimes the application conditions of a term may not be easily graspable. This happens because application conditions, like grammatical rules, are acquired most often tacitly.

Application conditions should be thought of as semantic rules analogous to grammatical rules; just as competent speakers must be masters of following grammatical rules, but need not be capable of stating them ..., so must competent speakers be masters at following the semantic rules-but need not be capable of stating them (Thomasson, 2015, p. 92).

Therefore, similarly to what often happens with grammatical rules, attempts to express application conditions in clear formulations may be tricky. Intrinsically vague terms are even more challenging. "Some questions (e.g., 'Is there a heap on my patio?') may be difficult to answer, even for those who have mastered the rules of use of the terms" (Thomasson, 2015, p. 114). Clarificatory conceptual work is required:

In such cases distinctively philosophical work may help in attempting to figure out and make explicit what the rules of use for our terms and concepts are, and also in determining which questions may simply be unanswerable owing to the vagueness or indeterminacy in the corresponding concept. But this is conceptual philosophical work (Thomasson, 2015, p. 114).

The second sort of problems associated with Schema (E) arises when the application conditions are clear, but it is hard to establish whether they are fulfilled or not. Thomasson mentions as an example the laborious task of establishing whether ivory-billed woodpeckers still exist or not (Thomasson, 2015, p. 113). She notices, however, that the difficulties of this task are not to be addressed by philosophers: "it is work for scientists or investigative journalists, not for a distinctively philosophical discipline of ontology" (Thomasson, 2015, p. 114).

The third sort of difficulty associated with Schema (E) arises from philosophical technical terms. They may have divergent sets of clear-cut application conditions defined by philosophers, but we cannot rely on ordinary language to decide which one is correct.

Many ontological disputes might be understood as implicitly disputes about what it takes for there to be, for example, fictional characters, numbers, properties, propositions, and so on, and the work may be difficult and contentious - especially where the terms used are distinctively philosophical terms that lack rules of use established by ordinary English speakers. But it is not a matter of figuring out what 'really exists' (Thomasson, 2015, p. 114).

As the above quotations show, in all cases where difficulties may arise, Thomasson points out that

1 Epistemically metaphysical methods are those that are neither empirical investigation nor conceptual analysis. Thomasson (2015, p. 17) takes this characterization from Sider (2011, p. 187). 
nothing beyond empirical or conceptual work is demanded. "[T]here are no deep metaphysical mysteries to be solved here, nor is there any need to appeal to the best 'total theory' or undertake any epistemically metaphysical investigations to resolve existence questions" (Thomasson, 2015, p. 114). But does this guarantee that controversial debates will not arise?

I do not think so. First, because the kinds of side issues to easy-arguments examined here are likely to yield controversial, sometimes highly contentious, debates. As long as the side issues are not settled, the easy-argument cannot succeed in answering the internal question. Even if the side issues can all be solved by empirical or conceptual means, this does not guarantee that their solution will not lead to contention. More often than not, no trivial and straightforward method will be available for solving them. This becomes specially clear in debates about the clarification of the application conditions for philosophical technical terms, such as properties, propositions, possible worlds, etc. Easy ontology cannot offer any guidance in solving them, not only because ordinary language is silent about their application conditions, but also because there is no trivial way of fixing their application conditions.

If serious controversies arise about side issues, then the debate can be diverted from the proposed easy-argument to its associated side issues. This can make the proposed easy-argument become secondary, in the sense that its force will depend on the resolution of more fundamental matters for which there is no easy approach. Thus, the initial apparent obviousness and triviality of the question is lost.

Furthermore, even when no side issue arises, an easy-argument may always be rejected in favour of metalinguistic negotiation. An objector may argue that, even if an easy-argument leads to the existence of Xs, it would be more advantageous to stop talking in terms of Xs. In this case, the debate may be diverted to metalinguistic negotiation, and the acceptance of the easy-argument may become dependent on the solution of the metalinguistic debate. Since there is no trivial and straightforward method of solving metalinguistic negotiations, we have, again, a debate to which easy ontology can offer no guidance.

Thomasson is aware of the potential that easy-arguments have to yield controversies. She claims that to say that existence questions are easy to answer is not to say "that they can be answered quickly without much effort, but rather [that] they may be answered either by straightforward empirical means [or logical analysis]" (Thomasson, 2017a, p. 7). In this sense, what makes easy ontology easy is not its reliance on easyarguments, but rather its reliance on empirical or conceptual work as capable of solving all reasonable controversies that may arise. Thomasson says:

The crucial advantage of easy ontology is its ability to demystify the epistemology of metaphysics. As a result, what the defender of easy ontology is committed to is the idea that, to the extent that they can be understood as sensible, metaphysical debates and claims can be understood as involved in conceptual and/or empirical work (Thomasson, 2017a, p. 18).

Nevertheless, given that conceptual and/or empirical work can be tough, in which sense is easy ontology still easy? As Button puts it, Thomasson's explanations suggest that the 'easy' in 'easy ontology' 'is to be read in a 'technical sense', as a shorthand for the idea that 'no epistemically metaphysical work is required' in answering existence questions" (Button, 2016, p. 12). If this is the case, Button suggests that the name 'easy ontology' is better conceived of as a misleading slogan. But, he also points to a more serious problem:

Thomasson repeatedly describes the inferences in her favoured easy-arguments as 'trivial'. Unless 'trivial' is meant in a suitably technical sense, this is wrong. The putative inferences to the existence of properties 
or propositions are highly non-trivial, and even if they are ultimately legitimate inferences, this has yet to be shown (Button, 2016, p. 12).

In fact, Thomasson states clearly that reliance on trivial inferences is an essential characteristic of easy ontology.

I will call an approach to answering (a particular range of) existence questions an 'easy' approach provided it shares the following two features: holding that all well-formed existence questions may be answered by conceptual and/or empirical work (requiring nothing 'epistemically metaphysical'), and that at least some disputed existence questions may be answered by means of trivial inferences from uncontroversial premises (Thomasson, 2015, p. 128).

Thus, 'easy ontology' is not intended to be a misleading slogan. Thomasson really believes that her methodology can solve some contentious existence questions trivially. But, is there any disputed existence question that can really be settled by means of trivial inferences from uncontroversial premises? I submit that the inferences licensed by Schema (E) will rarely be trivial, because they would be trivial only if everything else - all the sources of controversies linked with application conditions, fulfillment of them and metalinguistic negotiation-were already settled. Because ordinary language is likely to yield many legitimate concerns regarding these matters, and because these concerns cannot themselves be trivially settled, I believe that the inferences involved in putative easy-arguments will hardly be trivial. To illustrate this, in the next section I discuss some aspects of the debate about the existence of human races.

\section{Human races}

Do races exist? In easy ontology, the way one should approach this question depends on whether it is taken as external or internal. If the question is conceived of as external, then it leads to metalinguistic negotiation. This is the case, according to Thomasson (2017a, p, 16-17), of the debate between Kwame Appiah and Sally Haslanger. I will address this point later in this section. First, let us consider the event in which the question 'Do races exist?' is conceived as internal. In such cases, easy ontology suggests that we should try to solve it through an easy-argument. A tentative easy-argument for the existence of races may be this:

(a) Donald Trump is White.

(b) The race of Donald Trump is White.

(c) Therefore, there are races.

As expected, this argument is hardly convincing for those involved in debates on the ontology of race. Without addressing easy ontology directly, Spencer expresses resistance against such straightforward arguments for the existence of races:

$[\mathrm{R}]$ acial realism might seem to be trivially true. For example, it is widely accepted in the natural sciences that if you can show that even one member of a kind exists, then that kind exists. For instance, that is the strategy chemists use to identify new elements, and it is the strategy that biologists use to identify new species. Given this assumption, and given that, say, Asians, Blacks, Native Americans, and Whites are paradigms of races in current American English, is not it trivially true that race itself exists? Well, it is not that simple (Spencer, 2018a, p. 1). 
As we have seen above, things can get complicated in easy ontology when the application conditions of the term in question are somewhat obscure, or, granted that the application conditions are somehow fixed and clear, things can get complicated when there is tricky empirical or conceptual work to be done in order to show that the application conditions are fulfilled. Spencer's objections to straightforward arguments for the existence of races correspond to these two legitimate sources of controversies. His first objection is about the fulfillment of application conditions:

First, we need to do some metaphysics. To be specific, we need to know what is sufficient for existing in order to say that Asians, Blacks, Native Americans, and Whites exist. This may sound strange. But think about this. Is not it true that Tyrannosaurus rex is a paradigm species of the genus Tyrannosaurus? But does that fact make it true that the genus Tyrannosaurus exists? Of course not, because we need to show that the instances of a kind exist in order to use those instances as evidence that the kind itself exists (Spencer, 2018a, p.1).

The fact that Spencer claims that "some metaphysics" has to be done seems to suggest that he is engaged in hard ontology. But, as the example of Tyrannosaurus makes clear, this is not the case. He is demanding nothing more than empirical evidence for the existence of Asians, Blacks, etc. They can fulfill the application conditions of the term 'race' only if they themselves exist. And then difficulties arise, because the terms 'Asian', 'Black', etc., do not have clear application conditions. There is no common understanding on what amounts to be Asian, Black, etc. This casts doubt on the premise (a) of our tentative easy-argument for races. We cannot be sure that Donald Trump fulfills the application conditions of the term 'White' because we are not sure about its application conditions. Substituting Queen Elizabeth II for Donald Trump will not help, because the problem is in the applications conditions of 'White', not in the individual we took. Hence, we cannot be sure about the existence of Whites. Consequently, we cannot confidently assert that White fulfills the application conditions of the term 'race' either.

This shows that an easy-argument may depend on other easy-arguments. The higher-order easy-argument for races depends on lower-order easy-arguments for Whites, Blacks, etc. Indeed, if this is so, we can go back to Thomasson's easy-argument for the existence of properties mentioned above, and ask-now in a completely legitimate easy-ontological move-if redness itself exists. Given that in the world we find only red things, not redness itself, empirical work will not help. This is to be solved by conceptual analysis. But can this be done without reviewing philosophical debates about properties and universals, as Thomasson claims in the excerpt quoted above? This seems unlikely. Hence, her argument for the existence of properties is no longer easy and trivial. A chain of easy-arguments may lead to even more controversies.

Spencer's second objection against straightforward arguments for the existence of races is about the application conditions of the higher-order term 'race':

Second, we need to do some linguistics. In particular, we need to know what "race" means in the relevant context in order to say that any particular group exists as a race in that context. This investigation is needed because while it may be true that Asians, Blacks, Native Americans, and Whites exist, it may turn out to be false that each one is a race. For example, Blum (2002,137-146) has argued that Asians, Blacks, Native Americans, and Whites exist, but do not exist as races given the high bar for what counts as a race in current American English (Spencer, 2018a, p. 1).

Races may exist, but the application conditions of 'race' may rule out Asians, Blacks, etc., as being 
races. This casts doubt on the premise (b) of our tentative easy-argument for races. Donald Trump may be White, but Withe may turn out to be not a race. To settle this question, the application conditions of 'race' must be clarified. But is 'race' a technical or an ordinary term? Its application conditions and, consequently, the answer about the existence of races may differ in each case.

[W] hen the linguistic context of asking whether race is real is restricted to "race" as understood among biologists (e.g., "race" as a synonym for "subspecies" or "ecotype"), then some philosophers and biologists have argued that race isn't real. However, some philosophers and biologists have argued that race is real in a biological sense of "race". When the linguistic context of asking whether race is real is restricted to some ordinary language or dialect (e.g., English, American English, etc.), the most common answer among metaphysicians of race is that race is real. However, more than a few metaphysicians of race have argued that race is not real in the relevant ordinary sense (Spencer, 2018a, p. 2).

Thomasson admits, as we have seen above, that issues can become more complicated when technical terms are at stake. Easy ontology takes ordinary language usage as the final arbiter of existence questions, but this is feasible only to the extent that the term in question is not technical and its ordinary use is unproblematic. But clearly, this is not the case of 'race': it is also a technical term, and both its ordinary and technical uses are highly problematic. Based on surveys about the ordinary use of racial terms in the United States, Spencer concludes that "one plausible interpretation of the data is that there is no single or dominant meaning of 'race' among American English speakers" (Spencer, 2018b, p. 12). In this scenario, easy ontology cannot offer any guidance.

Even if ontologists of race embraced easy ontology devotedly, they could not have any hope of settling the issue in trivial, straightforward ways. The difficulties have nothing to do with meaningless hard ontology, nor with pragmatic external questions. They legitimately arose from a proposed easy-argument. This easyargument is not likely to be successful unless all the difficulties had been settled beforehand. Consequently, the easy-argument becomes secondary. It is best seen as only a motivation to launch a debate about more fundamental issues.

Conceiving of the question 'Do races exist?' as external involves denying or affirming the existence of races for reasons not linked to Schema (E). These reasons may have to do with metaphysical beliefs-e.g., "races do not exist because they are social constructions, and social constructions do not really exist". In the easy ontologist account, this would be meaningless hard ontology. However, the reasons to take the question as external may have to do with pragmatic concerns. In this case, this would be legitimate metalinguistic negotiation. According to Thomasson (2017a, p. 16-17), the debate between Appiah and Haslanger can be seen in this way.

Appiah (2006) denies that races exist. For Appiah, folk races presuppose the idea of intrinsic racial essences that would be inherited from one's parents. Appiah assumes that these racial essences must take the form of biological facts. But, given that no such biological facts have been found, races do not exist. This reasoning can be seen as an application of Schema (E). Nevertheless, Appiah suggests: "If you want to say there are races, understand race as a social identity" (Appiah, 2006, p. 381). Here the metalinguistic negotiation can start, for Appiah admits that we can carry on talking about race, once we have changed its meaning.

Referring to Appiah's position, Haslanger asks: "Does it really matter whether we say, for example, that there are no races but there are racial identities, rather than that there are races but they are social rather than natural?" (Haslanger, 2012, p. 385). For Haslanger, what matters is that our concept of race must serve 
a purpose, namely, to fight against injustice (Haslanger, 2000, p. 36). She is openly engaging in metalinguistic negotiation when she proposes an "ameliorative definition" of 'race'. She defines races, roughly, as groups that are privileged or subordinated in function of some bodily features presumed to be due to ancestral links to a certain region (Haslanger, 2012, p. 384; 5, p. 44). She is aware that her definition of 'race' does not capture the ordinary sense of the term. "My priority in this inquiry is not to capture what we do mean, but how we might usefully revise what we mean for certain theoretical and political purposes" (Haslanger, 2000, p. 34). Her definition aims to make explicit that the categorization of people into races promotes unfair relations of subordination and privilege.

Ontologically, Haslanger admits that races exist as social categories, so long as we indeed use racial terms. However, given the oppressing character of races, she advocates for their elimination, what amounts to stop using racial terms. Thomasson takes Haslanger's position as a clear illustration of metalinguistic negotiation:

Debates about the existence of races, then, may —at the most deep and important level—be understood as engaged in metalinguistic negotiation about what function we want race concepts to serve (if any), and whether our purposes would be better served by reshaping the contours of our concept of race or doing away with it altogether, or replacing it with something else (say, a concept of racial identity). Haslanger's approach to debates about the existence of races makes unusually lucid the role of practical and functional questions in such debates - making explicit the crucial role of what I am calling 'metalinguistic negotiation' in such existential debates, where this is usually left behind the scenes (Thomasson, 2017a, p. 17).

Haslanger's position is a good example of how metalinguistic negotiation can take central stage in ontology. However, it is also a good example of how easy ontology can offer no guidance in such matters. Although legitimate from the perspective of easy ontology, this debate cannot be settled by easy and straightforward methods. Perhaps the only gain here is the understanding that ontological debates can be highly polarized even if mysterious metaphysical claims are put aside.

Regardless of whether the existence question is taken as internal or external, there is no hope of settling the ontological debate about races through trivial inferences from uncontroversial premises. However, admittedly this does not show that there is not any situation where an easy-argument can, by itself, solve an ontological debate. Indeed, anyone could anticipate that in contexts where ordinary language usage is highly confusing, easy-arguments would be ineffective. But the fact that easy ontology fails in this context does not imply that it will fail everywhere. There may be some unproblematic contexts in which easy-arguments can trivially answer existence questions.

This is a cogent objection. Since I cannot evaluate every existence question, this objection cannot be completely put aside. However, I can make my point stronger by addressing a completely different class of terms with regard to confusing language usage, namely numerical expressions. Numbers are used with clearness and regularity, at least in languages such as English. Thomasson gives many easy-arguments for the existence of numbers, and Button himself agrees that numbers can be called in defense of easy ontology. In the next section, I show that it is not that simple.

\section{Numbers}

Do numbers exist? If this question is taken as a pragmatic external question, it amounts to asking 
whether we should adopt number-language or not. Disputants, then, are seen as engaged in metalinguistic negotiation. Thomasson says: "On this view the nominalist in philosophy of mathematics would be best seen as suggesting that we do away with the noun-use of number terms, and instead make do with a nominalistic language" (Thomasson, 2015, p. 41). The platonist, in turn, would be best seen as suggesting that we should use number terms as nouns. It is clear that, when it comes to metalinguistic negotiation, no trivial and straightforward solution is available.

But easy ontology is supposed to offer trivial and straightforward answers when the existence question is taken as internal. In this case, Thomasson believes that easy-arguments can straightforwardly answer it. In fact, numbers are among her favorites examples of entities whose existence can be easily established. In Thomasson (2017b), she offers the following easy-argument for numbers:

(a) There are exactly three apples on the table.

(b) The number of apples on the table is three.

(c) There is a number that is the number of apples on the table.

Thomasson explains that (a) analytically entails (b), and that the conclusion (c) follows from the rules of use "that introduce terms like 'the number of xs' as nouns" (Thomasson, 2017b, p. 769, footnote 1). Because the expression 'the number of apples' works as a noun and has a referent- three-, we can be sure that the application conditions of the term 'number' are fulfilled and, therefore, that at least one number exists.

At first sight, it seems that the many controversies which may arise regarding other kinds of entitiessuch as races_-are not likely to arise regarding numbers. Button believes that, when it comes to numbers, even if we need to invoke a Context Principle, this would not make the case for numbers less easy:

[W] hilst there is no guarantee that existence questions can be answered straightforwardly, we might get lucky in certain cases. Indeed, I envisage the following defence of easy ontology:

To assess the easy-argument (1n)-(3n), I concede that we must invoke the Context Principle. But this does not yet make ontology difficult. After all, anyone who is competent in using numerical terms will be equally competent in handling the claims (in)-(iiin) from Subsect. 2.2. And such claims show that 'the number of bagels' really does behave as a term in (2n). So, on the basis of claims that lie readily to hand for an ordinary speaker, we can easily see that the easy-argument (1n)-(3n) is good.

I am sympathetic to this line of thought, in the specific case of numbers (Button, 2016, p. 9).

The easy-argument to which Button refers is similar to that offered by Thomasson. It starts with the premise " $(1 \mathrm{n})$ there are four bagels", from which it is inferred "(2n) the number of bagels is four" and, finally, "(3n) there are numbers" (Button, 2016, p. 2). The crucial point that guarantees the second inference, according to Button, is that the expression 'the number of bagels' in 2n "really does behave as a term". Behaving as a term means, for Button, that it is a referring expression in ordinary language (Button, 2016, p. 5).

Thomasson highlights that the belief that numbers are referring expressions also enables neo-Fregeans to establish the existence of numbers easily:

[T] he philosophy of mathematics that is commonly called 'neo-Fregean' ... takes off from Frege's view that objects are simply the correlates of singular terms, and that in general ontological categories are to be identified by way of the logical categories of our expressions (e.g, as singular terms, predicates, etc.) 
... This enables neo-Fregeans to offer 'easy' arguments for the existence of numbers (Thomasson, 2015, p. 133).

According to Thomasson, the neo-Fregean easy-argument may start with an uncontroversial truth that does not use the term 'number': “The cups and the saucers are equinumerous". From this and Hume's Principle, a derived claim is obtained: "The number of cups $=$ the number of saucers". Then, the final conclusion follows this way:

But since the derived claim is a true identity claim, they hold, we are entitled to conclude that the singular terms in it ('the number of cups' and 'the number of saucers') refer, and so that there are numbers. This approach ... apparently resolves an ancient ontological problem by starting from an uncontroversial truth that does not make use of the disputed concept (number) or make reference to the disputed entities (numbers) at all, and making use of trivial inferences (Thomasson, 2015, p. 134).

All these easy arguments rely on the same supposition that the expression 'the number of xs' is a referring expression, and that its referent is a number. Although many philosophers usually take for granted that it is, this is by no means an established uncontroversial truth, at least among linguists. Given that easy ontology relies on ordinary language usage for solving existence questions, the opinion of linguists is relevant here, and there is no consensus among them on this matter. Some linguists believe that numerical expressions do refer to numbers (e.g., Hurford, 1975), whereas others deny this (e.g., Wiese, 2003; Mengden, 2010). The important point for my argumentation, however, is that the issue is controversial, and the controversy does not arise from metaphysical concerns.

According to Wiese (2003, p. 79), counting words-the numerical expressions we recite when counting-are non-referential terms:

unlike other words, [counting words] do not have any meaning, they do not refer to anything in the outside world. This is because they are not names for numbers, they are numbers. Counting words are tools that we use in number assignments, and for this job they do not need any referentiality.

Wiese's opinion is not based on a anti-platonist belief. It is based on her analysis of the role counting words play on ordinary language. One reason to believe that counting words are non-referring terms comes from the way we learn these words. Suppose you are stranded in a remote island where you do not understand the native's language. You could learn the meaning of many nouns by ostension, but you could not learn counting words_-nor other numerical expressions_-by pointing to things and asking how the natives call them. Rather, you could try to pick up the initial counting words by observing native's employing them in the process of counting. Then,

Once you know the first two or three elements of a counting sequence, you can learn more counting words just by reciting them and making people continue with the sequence. This way, you could learn every counting word just by its position within the sequence, with no need to refer to anything in the world (Wiese, 2003, p. 80).

And this happens, of course, also with no need to refer to anything in a platonic realm, or to anything that would exist in any other sense. Translation provides another illustration of the non-referentiality of counting words: 
Whereas you know that CAT translates into French as CHAT because both words refer to the same things, you know that FOUR in English corresponds to QUATRE in French because both words have the same position within their respective counting sequences (Wiese, 2003, p. 80).

Cardinal number words, on the other hand, do refer, but not necessarily to numbers. We use cardinal number words to indicate how many objects there are in a set. But this can be made without referring to numbers. Wiese (2003, p. 269) says: "the cardinal number word 'four' refers to a cardinality that matches that of the counting sequence up to FOUR". This idea can be spelled out in the following way. We count a set of things by associating each thing with a counting word, starting from 'one' and following the usual sequence, never using a counting word more than once, nor associating a same thing with more than one counting word. This process establishes a one-to-one-mapping from things onto an initial segment of the counting sequence. When this process is finished, the last counting word we had used corresponds to the cardinality of the set. Thus, when we say that a set has, e.g., five elements, the symbol 'five' is not used to refer to an object. The expression 'the set has five elements' means that the sequence of counting words from 'one' to 'five' has as many elements as that set. Using neo-Fregean's terminology, one could say that the expression 'the set has five elements' only means that the elements in the set and the sequence of counting words from 'one' to 'five' are equinumerous. And that is all. In ordinary usage, we do not need to carry on by introducing numbers as referents of numerals by Hume's Principle. Thus, when we say "the number of apples on the table is three", this means that there is a one-to-one mapping from the sequence <'one', 'two', 'three'> onto the set of apples. In this sense, Thomasson's easy-argument (a)-(b) quoted in the beginning of this section is best seen as establishing the existence of one-to-one mappings from initial sequences of the series of counting words onto sets of things. Are these one-to-one mappings numbers? Frege refused vehemently this idea. ${ }^{2}$

Of course, this brief discussion neither establishes whether numbers exist or not, nor conclusively show that numerical expressions do not refer. But it is enough to launch a debate about the side issues associated with easy-arguments for numbers. Which numerical expressions are really referring terms? Regarding numerical expressions that do refer, what do fulfill their application conditions? Do one-to-one mappings of counting words onto sets of things fulfill the application conditions of referring numerical expressions? These are, in my opinion, some of the relevant questions, if I were to formulate them in easy ontology terms.

Before concluding this section, a few remarks are in place. The issue about the (non-)referentiality of number expressions discussed here is not an instance of metalinguistic negotiation. Wiese is not suggesting that we should stop using counting words as referring terms in favor of using them as non-referential terms. She is not presenting an alternative interpretation of numbers and numerical expressions either. As a linguist, she is concerned with what is really going on in ordinary language when we use numerical expressions. It is a matter to be solved, in part, empirically, for it depends on how people really use numerical expressions. Undoubtedly, this can get even more controversial if the analysis is broadened to encompass the use of numerical expressions in mathematics. One may even claim that, in mathematics, the use of numerals must be referential. To the extent that this claim has to be supported by argumentation that is unlikely to be trivial and straightforward, this underscores my claim that the question about the existence of numbers is not easy.

\footnotetext{
2 Since there is no characteristic manner in which an aggregate of matter could be counted (Frege, 1960, p. 29), the codomain of these mappings (sets of things) would be empty. For example, the sequence "one, two" does not map directly onto anything in the world, since there is nothing in the world that is intrinsically an instance of two.
} 
To sum up, even if we take the question 'Do number exist?' as internal, and even if we adhere to easy ontology's methodology, easy-arguments cannot settle this question, unless the questions of which numerical expressions are referential, and of what they refer to, are settled beforehand. These questions do not have a trivial and straightforward answer; even so, we do not need to recruit epistemically metaphysical methods. Empirical study of ordinary language usage, assisted by conceptual analysis, will do. This is the same point I made above about races: once controversies arise, easy-arguments become secondary for existence questions. While the issue about the referentiality of number words is not solved, we do not know whether numbers exist or not, but we do know that the question is not easy.

\section{Conclusion}

According to Thomasson (Thomasson, 2015, p. 128, quoted above), an approach to existence questions is easy if it has two features: (a) only conceptual or empirical methods are employed; and (b) at least some disputed existence questions are trivially and straightforwardly answered. In this essay, I maintained that the last desideratum is not likely to be achieved by Thomasson's easy ontology. There are many ways by which puzzling side issues can became more important than the easy-arguments that were supposed to trivially solve existence questions. I showed that in two completely different ontological discussions, those about races and numbers, the proposed easy-arguments leave room for complex side issues which turn out to be more relevant than the initial easy-arguments.

Easy-arguments can be no more than a motivation to start an ontological debate. From the first impression that the existence of properties, numbers, or races can be inferred from ordinary language usage, we start to discuss if these things really exist, that is, if ordinary language in fact entails their existence, if the terms are better seen as technical, if their application conditions are actually fulfilled, if it is better to dispense with them altogether, etc. All these possible points of contention hinder a trivial and straightforward answer; however, these discussions can be conducted satisfying the first desideratum of easy ontology. No mysterious metaphysics is needed. But ontology free of mysterious metaphysics may still be hard.

The real ontological work involves addressing the several side issues that may arise from the so-called easy-arguments - "side" issues, it must be added, only from the perspective of tentative easy-arguments. In fact, these are the central issues, for which unfortunately there are no trivial and straightforward answers. Thomasson may have underestimated the importance and difficulty of these issues. Quoting Button again, "[o]rdinary language is a wildly complicated phenomenon" (Button, 2016, p. 9).

\section{References}

Appiah, K. (2006). "How to Decide If Races Exist”. In: Proceedings of the Aristotelian Society 106, pp. 365-382.

Button, T. (2016). “Deflationary metaphysics and ordinary language”. In: Synthese, pp. 1-25.

Carnap, R. (1983). “Empiricism, Semantics and Ontology”. In: Philosophy of Mathematics: selected readings. Ed. by P. Benacerraf, H. Putnam. Cambridge: Cambridge University Press, pp. 241-257.

Frege, G. (1960). The Foundations of Arithmetic. New York: Harper Torchbooks.

Haslanger, S. (2000). "Gender and race:(What) are they?(What) do we want them to be?”. In: Noûs, 34.1, pp. 31-55. 
Haslanger, S. (2012). Resisting Reality: Social Construction and Social Critique. New York: Oxford University Press.

Hurford, J. (1975). The Linguistic Theory of Numerals. Cambridge: Cambridge University Press.

Mengden, F. (2010). Cardinal Numerals: Old English from a cross-linguistic perspective. Berlin: De Gruyter Mouton.

Sider, T. (2011). Writing the Book of the World. New York: Oxford University Press.

Spencer, Q. (2018a). “Racial realism I: Are biological races real?”. In: Philosophy Compass, 13.1.

Spencer, Q. (2018b). “Racial realism II: Are folk races real?”. In: Philosophy Compass, 13.1.

Thomasson, A. (2015). Ontology made easy. New York: Oxford University Press.

Thomasson, A. (2017a). “Metaphysical Disputes and Metalinguistic Negotiation”. In: Analytic Philosophy 58.1, pp. 1-28.

Thomasson, A. (2017b). "Why we should still take it easy”. In: Mind, 126.503, pp.769-779.

Wiese, H. (2003). Numbers, Language, and the Human Mind. Cambridge: Cambridge University Press.

Artigo recebido em: 18 de fevereiro de 2020

Artigo aceito em: 10 de março de 2020 